\title{
Synthesis of nano-particle and highly porous conducting perovskites from simple in situ sol-gel derived carbon templating process
}

\author{
WEI ZHOU, RAN RAN, ZONGPING SHAO*, WANQIN JIN and NANPING XU \\ State Key Laboratory of Materials-oriented Chemical Engineering, Nanjing University of Technology, \\ No. 5 Xin Mofan Road, Nanjing, JiangSu 210009, P.R. China
}

MS received 14 February 2009; revised 19 August 2009

\begin{abstract}
Nano-sized $\mathrm{La}_{0.6} \mathrm{Sr}_{0.4} \mathrm{Co}_{0.2} \mathrm{Fe}_{0.8} \mathrm{O}_{3-\delta}$ (LSCF) and $\mathrm{La}_{0.8} \mathrm{Sr}_{0.2} \mathrm{MnO}_{3-\delta}$ (LSM) oxides were synthesized by a simple in situ sol-gel derived carbon templating process. Nano-sized LSCF-carbon and LSM-carbon composites were first obtained with a grain size of 20-30 nm. Further calcination of the obtained composites under air resulted in the nano-sized pure-phase perovskites with crystalline size of as small as $14 \mathrm{~nm}$. Such a decrease in crystalline size of perovskite via the indirect calcination process was ascribed to the suppressing effect of carbon in the grain growth of perovskite. Furthermore, when the $i n$ situ created carbon was applied as a template for pore forming, a highly porous perovskite sintering body packing from the nano-sized perovskite oxide was obtained.
\end{abstract}

Keywords. Perovskite; EDTA-citrate; sol-gel; carbon template; porous ceramics.

\section{Introduction}

Perovskite is a type of mixed oxides with the general formula of $A B O_{3}$, where $A$ and $B$-site metal ions can both be partially substituted without impact on its lattice structure. Via the strategy of substitution, certain doped perovskite oxides with oxygen ionic, electronic or mixed oxygen ionic and electronic conductivity can be obtained Such materials find wide applications in catalytic oxidation, electrolysis, fuel cells, metal-air battery, and ceramic oxygen separation membrane (McEvoy 2001; Shao and Haile 2004). $\mathrm{La}_{x} \mathrm{Sr}_{1-x} \mathrm{Co}_{y} \mathrm{Fe}_{1-y} \mathrm{O}_{3-\delta}$ and $\mathrm{La}_{x} \mathrm{Sr}_{1-x} \mathrm{MnO}_{3-\delta}$ are the two typical perovskite-type conducting oxides, which are the most applied cathode materials in solid oxide fuel cells (Tai et al 1995; Maguire et al 2000; Zhou et al $2008 \mathrm{a}, \mathrm{b})$. Both of them also show high activity for catalytic flameless combustion of hydrocarbons, and lowtemperature catalytic oxidation of environmental pollutant, such as CO and volatile organic compounds (VOC) (Fierro 1990; Petunchi and Lombardo 1990; Yamazoe and Teraoka 1990). Furthermore, $\mathrm{La}_{x} \mathrm{Sr}_{1-x} \mathrm{Co}_{y} \mathrm{Fe}_{1-y} \mathrm{O}_{3-\delta}$ is a promising material for ceramic oxygen separation membrane and cathode for metal-air battery (Teraoka et al 1985; Weidenkaff et al 2002).

Normally, the catalytic properties (chemical or electrochemical) of perovskite are closely related with its surface area, which is determined mainly by the particle size of the perovskite. Nano-structured materials have received

\footnotetext{
*Author for correspondence (shaozp@njut.edu.cn)
}

great attention from scientific and industrial communities due to their unique properties in physics and chemistry. As compared to the coarse-grained ones, nano particles not only possess higher specific surface area, but also have more significant surface phase in homogeneity, that may substantially improve the catalytic activity (Gunasekaran et al 1996; Liu et al 2002). Nano-particles can also reduce the sintering temperature obviously for pellet densification due to the high surface energy (Boutz et al 1995), which is beneficial for the application in ceramic oxygen separation membrane. For application as a cathode in solid oxide fuel cells, the perovskite should form a highly porous layer to minimize the diffusion polarization. Therefore, a high porosity of electrode is critical. On the other hand, a high electrode surface area is critical in order to minimize the oxygen activation polarization. The pores in electrode are created from the packing of the particles, while the surface area is contributed from the external surface area of the particles. Porous cathode built up from nano particles then has the advantage of high surface area and so low activation polarization (Zhang et al 2005). Furthermore, the support of perovskite over carbon, or the formation of carbon-perovskite mixture can substantially increase the dispersion of electrocatalyst, noticeable increase in the electrode performance of metal-air battery was observed due to the increase in effective surface area of electrocatalyst with the help of dispersion (Hayashi et al 1998; Weidenkaff et al 2002; Yuasa et al 2004; Imaizumi et al 2004).

In this paper, we described a simple in situ sol-gel derived carbon templating process, which is capable of 
easily synthesizing the above three types of functional materials, i.e. nano perovskite particles, nano perovskitecarbon composites, and highly porous perovskite sintering bodies. The syntheses of $\mathrm{La}_{0.6} \mathrm{Sr}_{0.4} \mathrm{Co}_{0.2} \mathrm{Fe}_{0.8} \mathrm{O}_{3-\delta}$ and $\mathrm{La}_{0.8} \mathrm{Sr}_{0.2} \mathrm{MnO}_{3-\delta}$ were investigated in this study. We applied a mixed EDTA-citrate complexing process for the molecule level mixing of the raw materials. The solid precursor then obtained was calcined under oxygen deficient condition at high temperature to simultaneously convert the organic into carbon and create the perovskite oxide. Therefore, a nano perovskite-carbon composite was obtained. By burning out the carbon with the following calcination under air at high temperature, pure phase nano-sized perovskite was obtained. The in situ created carbon was also used as a template for the formation of highly porous LSCF and LSM bodies.

\section{Experimental}

Analytical reagents of lanthanum nitrate, $\mathrm{La}\left(\mathrm{NO}_{3}\right)_{3} \cdot 6 \mathrm{H}_{2} \mathrm{O}$, strontium nitrate $\mathrm{Sr}\left(\mathrm{NO}_{3}\right)_{2}$, cobalt nitrate $\mathrm{Co}\left(\mathrm{NO}_{3}\right)_{2} \cdot x \mathrm{H}_{2} \mathrm{O}$, iron nitrate $\mathrm{Fe}\left(\mathrm{NO}_{3}\right)_{3} \cdot y \mathrm{H}_{2} \mathrm{O}$ and $\mathrm{Mn}\left(\mathrm{CH}_{3} \mathrm{COO}\right)_{2}$ were used as the starting materials for the synthesis of $\mathrm{La}_{0.6} \mathrm{Sr}_{0.4}$ $\mathrm{Co}_{0.2} \mathrm{Fe}_{0.8} \mathrm{O}_{3-\delta}$ (LSCF) and $\mathrm{La}_{0.8} \mathrm{Sr}_{0.2} \mathrm{MnO}_{3-\delta}$ (LSM). The synthesis of LSCF, as an example, was described as follows. Stoichiometric amounts of lanthanum nitrate, strontium nitrate, cobalt nitrate, and iron nitrate were mixed into an aqueous solution. Necessary amount of EDTA$\mathrm{NH}_{3} \cdot \mathrm{H}_{2} \mathrm{O}$ was added to the solution. After stirring under heating for a couple of minutes, citric acid solution was then added and the mole ratio of metal ions: EDTA: citric acid: $\mathrm{NH}_{3} \cdot \mathrm{H}_{2} \mathrm{O}$ was kept at $1: 1: 2: 10$. The solution was continuously heated at $80-100^{\circ} \mathrm{C}$ under stirring until a transparent gel was obtained, which was heated at $250^{\circ} \mathrm{C}$ in an electrical oven for solidification. The as-obtained solid precursor was then calcined at high temperatures under oxygen deficient condition for various times. For this calcination, the furnace was pre-heated up to the aimed temperature before the solid precursor within an enclosed ceramic crucible was put in. The sample was withdrawn from the furnace to the ambient atmosphere when the aimed calcined time was reached. Some of the obtained powders were further calcined under open air at high temperature to result in the pure perovskite powder. For the preparation of porous perovskite, the obtained carbon-templated powders were formed into pellets, which were then calcined at $1000^{\circ} \mathrm{C}$ to form highly porous sintering bodies. A heating and cooling rate of $5^{\circ} \mathrm{C} \mathrm{min}^{-1}$ was applied in this case.

The obtained powder or porous sintering bodies were characterized by powder X-ray diffraction, Fourier transform infrared spectroscopy, and scanning electron microscopy together with the energy dispersive X-ray (EDX) etc. Powder X-ray diffraction data were measured with a Bruker D8 advance diffractometer with $\mathrm{Cu} \mathrm{K}$ radiation $(\lambda=0 \cdot 15418 \mathrm{~nm})$. The crystallite domain sizes $(D)$ were examined from XRD peaks based on the Scherrer equation,

$$
D=0.9 \lambda \beta /(B \cos \theta),
$$

where $\beta$ is the $\mathrm{X}$-ray wavelength, $\theta$ the Bragg diffraction angle, and $B$ the calibrated half-peak width of the XRD lines. Fourier transform infrared spectroscopy (FTIR, Thermo Nicolet Corporation AVATAR-360) of the precursor and calcined powders was recorded from 4000$400 \mathrm{~cm}^{-1}$ by the $\mathrm{kBr}$ pellet method. The morphologies of the calcined powders or porous sintering bodies were observed using a field emission scanning electron microscope (FESEM, LEO1530). The porosity of the porous pellets was examined by Archimedes method using water.

\section{Results and discussion}

As mentioned previously, the preparation of carbon supported perovskite or perovskite-carbon composite is an effective way to increase the electrode performance due to the increase in the surface area of the electrocatalyst (perovskite). Complicated reverse Micelle method, reverse homogeneous precipitation method, or catalytic hydrocarbon dissociation reaction method has been successfully reported for the synthesis of carbon-perovskite composite (Hayashi et al 1998; Imaizumi et al 2004; Yuasa et al 2004). In those methods, either the perovskite or the carbon was pre-formed before mixing. In order to get a high dispersion of the perovskite, nano-sized perovskite or carbon was applied in the preparation.

In the previous study, we applied a combined EDTAcitrate complexing process for the synthesis of LSCF perovskite (Zhou et al 2006). With the help of EDTA and citric acid by chelating, the metal ions were mixed homogeneously in the molecule level in the precursor. The calcination at high temperature under air led to the simultaneous burn out of the organic and formation of perovskite. We recognized that a large amount of organic (EDTA: citric acid: total metal ions $=1: 2: 1$ ) was applied in the preparation. When the solid precursor was calcined under oxygen deficient condition, it would undergo pyrolysis to form solid carbon. If the perovskite oxide was simultaneously formed during calcination, a carbonperovskite composite could then be obtained. Assuming that all the $\mathrm{C}$ specie in the organic was able to be decomposed into solid carbon, the mole ratio of carbon to perovskite reached as large as $44: 1$. It suggests the practical feasibility of in situ carbon creation for carbonperovskite composite through the pyrolysis process.

The preparation of LSCF-carbon composite by this novel process was then tried. Figure 1 shows the X-ray diffraction patterns of the powders by calcination of the LSCF solid precursor at $900^{\circ} \mathrm{C}$ under oxygen deficient condition for various times. The samples with a calcination time of 5-20 min displayed mainly an amorphous 
crystal structure. Some weak diffraction peaks started to appear at a calcination time of $40 \mathrm{~min}$ with the two main newly appeared diffraction peaks at $31.3^{\circ}$ and $32.6^{\circ}$. Based on JCPDS card 34-1296, they were ascribed to the two strongest characteristic diffraction peaks of $\mathrm{K}_{2} \mathrm{NiF}_{4}$ structured phase at mirror index of $\langle 110\rangle$ and $\langle 111\rangle$, respectively and was referred to the $\mathrm{La}_{2-x} \mathrm{Sr}_{x} \mathrm{CoO}_{4}$ phase in this study. Some perovskite diffraction peaks also started to appear at a calcination time of $80 \mathrm{~min}$ and $160 \mathrm{~min}$. The appearance of diffraction peaks at $26.4^{\circ}$ and $44.9^{\circ}$ could be an indication of the formation of graphite. However, it is likely that the carbon was mainly in the state of amorphous structure since the peak intensity of graphite was very weak. Figure 2 shows the corresponding FTIR spectra of the samples within the range of $1000-400 \mathrm{~cm}^{-1}$. Only one adsorption band in FTIR spectra was observed, i.e. at around $\sim 595 \mathrm{~cm}^{-1}$, for the 5-20 min calcined samples. With the increase of the calcination time to $40 \mathrm{~min}$ or more, an additional adsorption band appeared at around $\sim 654 \mathrm{~cm}^{-1}$, and its intensity was strengthened with increasing calcination time. Figure 3 further gave out a comparison of FTIR spectra of the solid precursor, the samples calcined under oxygen deficient condition at $900^{\circ} \mathrm{C}$ for $5 \mathrm{~min}$ and $160 \mathrm{~min}$, and the sample calcined at $900^{\circ} \mathrm{C}$ for $5 \mathrm{~h}$ under air. According to the XRD diffraction patterns (figure 4 ), the $900^{\circ} \mathrm{C}$ calcined sample under air shows a pure-phase perovskite structure. The adsorption band at $594 \mathrm{~cm}^{-1}$ in the corresponding FTIR spectra was then ascribed to the stretch vibration $\mathrm{Co}-\mathrm{O}$ and/or $\mathrm{Fe}-\mathrm{O}$ in LSCF. Together with the XRD data and literature results (Rousseau et al 2004), the adsorption band at $\sim 654 \mathrm{~cm}^{-1}$ in the FTIR spectra was then ascribed to the $\mathrm{BO}_{6}$ stretch vibration in the $\mathrm{La}_{2-x} \mathrm{Sr}_{x} \mathrm{CoO}_{4}$ phase. Based on above analysis, it is likely that the perovskite phase

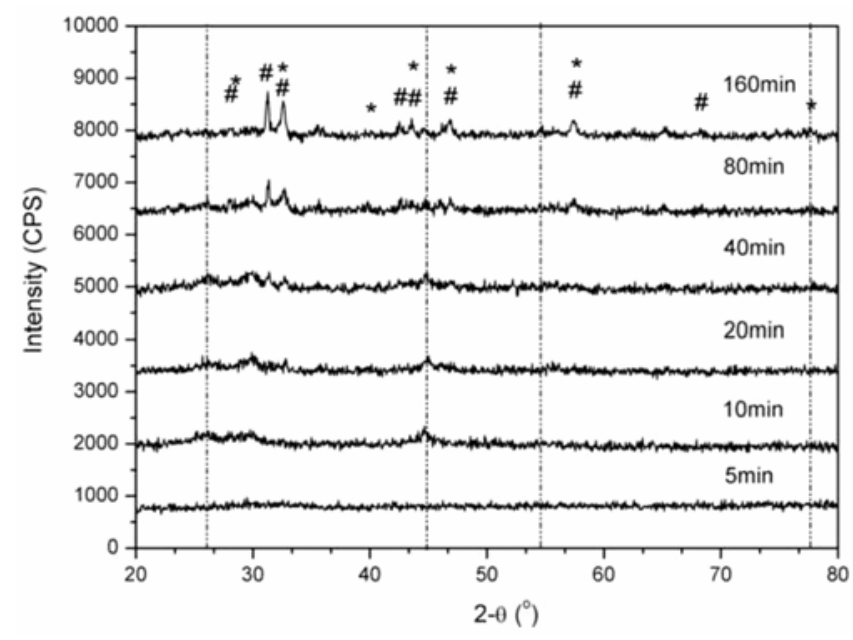

Figure 1. X-ray diffraction patterns of powders obtained by calcined EDTA-citrate-metal solid precursor at $900^{\circ} \mathrm{C}$ for $5 \mathrm{~min}, 10 \mathrm{~min}, 20 \mathrm{~min}, 40 \mathrm{~min}, 80 \mathrm{~min}$ and $160 \mathrm{~min}$ under oxygen deficient condition $\left(\#: \mathrm{La}_{2} \mathrm{CoO}_{4}, *\right.$ : perovskite, the dotted line positions should be the positions of peaks appearing for graphite). has already formed after calcination at $900^{\circ} \mathrm{C}$ under oxygen deficient condition for a short time (5-20 min). However, considering only when the powder calcined under oxygen deficient condition was further calcined at $900^{\circ} \mathrm{C}$ in oxygen did the perovskite phase appear, a further study should be carried out to verify the existence of perovskite.

The appearance of $\mathrm{La}_{2-x} \mathrm{Sr}_{x} \mathrm{CoO}_{4}$ phase with prolonged calcination time suggests the reduction of the perovskite oxide. During calcination at $900^{\circ} \mathrm{C}$, under oxygen deficient condition, the organic decomposition/oxidation and the perovskite formation reactions occurred simultaneously in the initial stage of calcination and led to the formation of the well dispersed carbon-perovskite mixture. With further increase of the calcination time, the solid-state reaction between carbon and LSCF occurred due to the highly reducibleness of $\mathrm{Co}^{3+}$. The reduction of $\mathrm{Co}^{3+}$ to $\mathrm{Co}^{2+}$ by carbon finally led to the collapse of the perovskite structure and the formation of $\mathrm{La}_{2-x} \mathrm{Sr}_{x} \mathrm{CoO}_{4}$ oxide. This explanation was supported by the fact that no such phases appeared during calcination of LSM solid precursor (figure 5). $\mathrm{Mn}^{3+}$ is much more stable than $\mathrm{Co}^{3+}$, and the reduction of $\mathrm{Mn}^{3+}$ by carbon was negligible. The observance of crystallized LSCF phase at more prolonged calcination time could be due to the crystalline size growth of the amorphous perovskite phase in the composite during calcination.

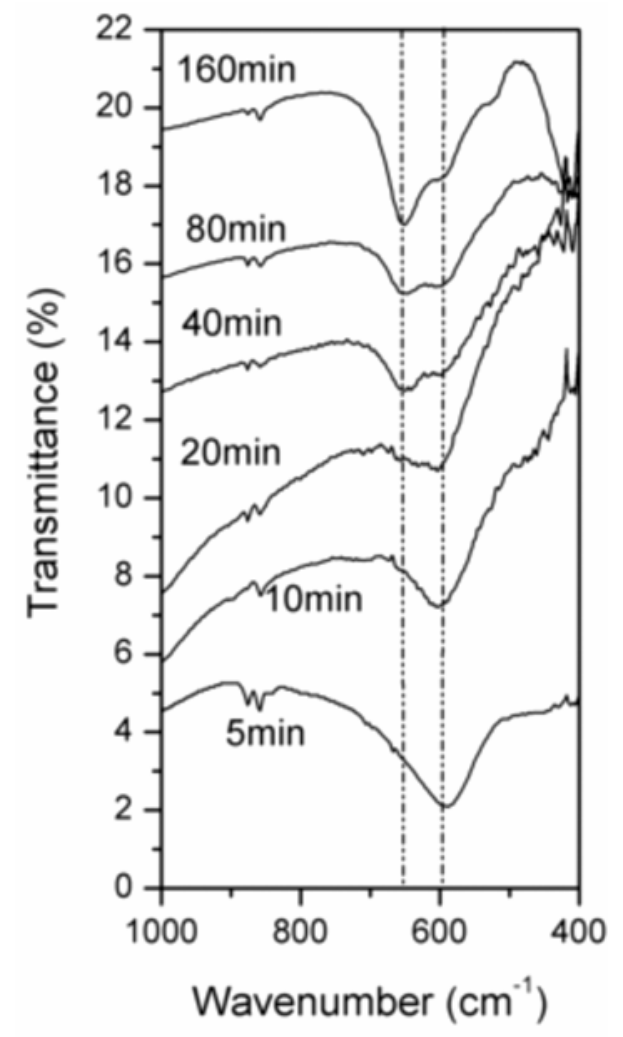

Figure 2. FTIR spectra of powders by calcined EDTAcitrate-metal solid precursor at $900^{\circ} \mathrm{C}$ for $5 \mathrm{~min}, 10 \mathrm{~min}$, $20 \mathrm{~min}, 40 \mathrm{~min}, 80 \mathrm{~min}$ and $160 \mathrm{~min}$ under oxygen deficient condition. 
Based on above analysis, an optimized calcination time and oxygen content in the atmosphere during calcination is critical for the formation of carbon-LSCF composite by the current in situ templating process. The typical

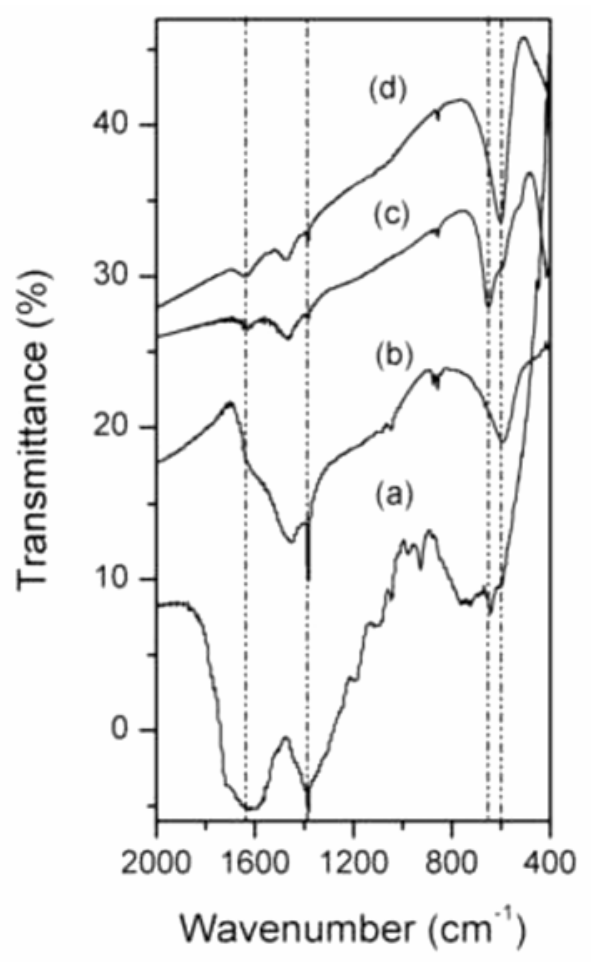

Figure 3. A comparison of the FTIR spectra of powders, (a) solid precursor from heat treatment of the gel at $250^{\circ} \mathrm{C},(\mathbf{b})$ and (c) the solid precursor calcined at $900^{\circ} \mathrm{C}$ under oxygen deficient condition for $5 \mathrm{~min}$ and $160 \mathrm{~min}$, respectively, and (d) powder calcined by the solid precursor under air for $5 \mathrm{~h}$ (pure phase perovskite). The bands at $594 \mathrm{~cm}^{-1}$ and $654 \mathrm{~cm}^{-1}$ are ascribed to the $\mathrm{Co}-\mathrm{O} / \mathrm{Fe}-\mathrm{O}$ and $\mathrm{BO}_{6}$ stretch vibrations in the perovskite structure, respectively.

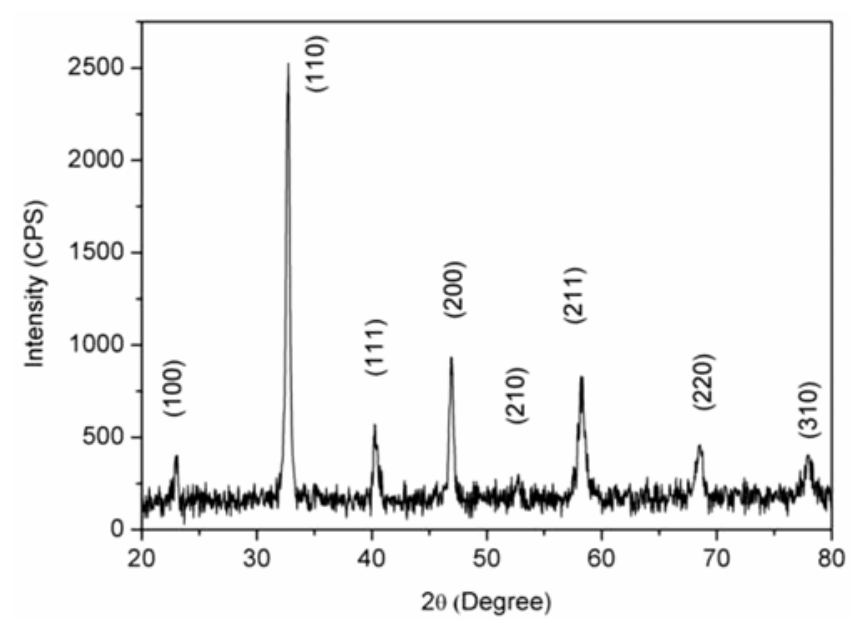

Figure 4. X-ray diffraction pattern of $\mathrm{La}_{0.6} \mathrm{Sr}_{0.4} \mathrm{Co}_{0.2} \mathrm{Fe}_{0.8} \mathrm{O}_{3-\delta}$ sample from calcination of its solid precursor under air at $900^{\circ} \mathrm{C}$ for $5 \mathrm{~h}$, the indexes are based on the rhombohedral crystal structure of $\mathrm{La}_{0.6} \mathrm{Sr}_{0.4} \mathrm{Co}_{0.9} \mathrm{Fe}_{0.1} \mathrm{O}_{3-\delta}$ (JCPDS card 49-0283). powder morphology of the as-prepared perovskite-carbon composite is shown in figure 6, the composite was nanosized and sphere shaped with primary grain with a grain size of $20-30 \mathrm{~nm}$. No segregated phase of perovskite or carbon was detected, which suggests the high dispersion of the two phases with each other.

For the preparation of single-phase perovskite oxides, direct calcination of the solid precursor from combined EDTA-citrate complexing process under air at high temperature has demonstrated promising results (Zhou et al 2006). Recently, the effectiveness of carbon template method for the synthesis of nano-structured/high surface area oxides has been recognized (Ozawa and Kimura

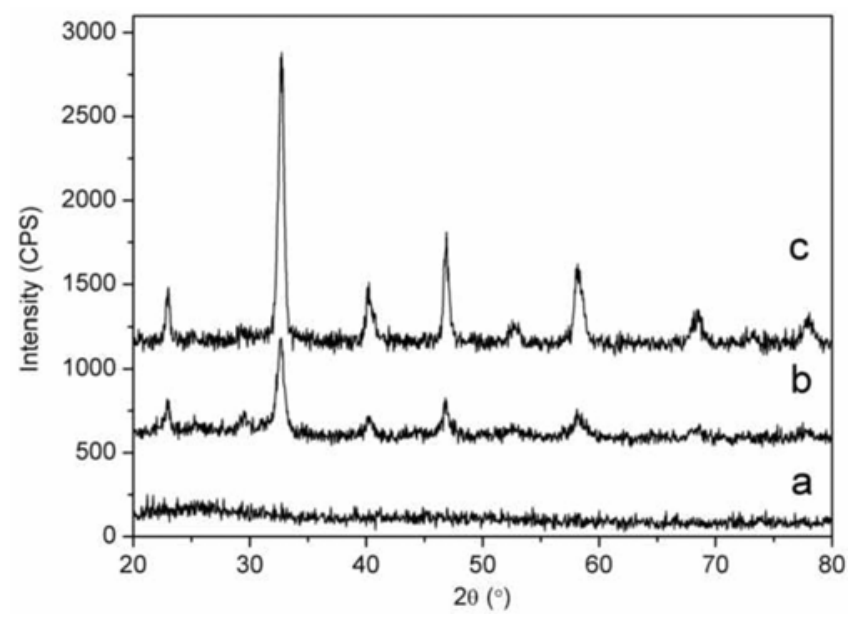

Figure 5. XRD patterns of LSM powders: (a) the solid precursor calcined at $900^{\circ} \mathrm{C}$ under oxygen deficient condition for $180 \mathrm{~min}$; (b) the sample obtained from (a) was further calcined under air at $600^{\circ} \mathrm{C}$ for $300 \mathrm{~min}$; (c) the solid precursor was directly calcined at $600^{\circ} \mathrm{C}$ for 300 min under air.

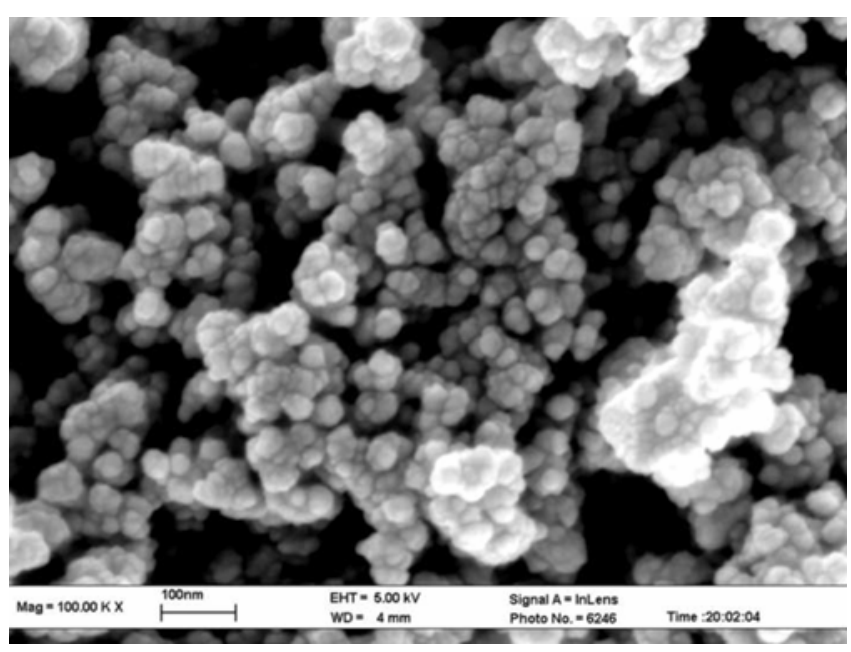

Figure 6. A typical morphology of the as-prepared carbonLSCF composite prepared by calcined solid precursor of LSCF via the EDTA-citrate combined complexing process, the composite is sphere shaped with the main particle size of 20-30 nm. 
1990; Schwickardi et al 2002; Liang et al 2004). By applying a high surface area activated carbon as an adsorbent, the metal ions can disperse over the carbon surface by impregnation. High surface area oxides, such as $\mathrm{CeO}_{2}$ and $\mathrm{CeO}_{2}-\mathrm{ZrO}_{2}$ etc have been synthesized after calcination of the precursor at high temperature. In this study, we tried another way for the preparation of LSCF via the carbon templating process. The solid precursor from EDTA-citrate combined complexing process was first calcined under oxygen deficient condition to convert the organic in the solid precursor to carbon, which was then further calcined at high temperature under air to burn out the carbon.

Figure 7 shows the X-ray diffraction patterns of the powders obtained by further calcination of the samples in figure 1 at $700^{\circ} \mathrm{C}$ for $5 \mathrm{~h}$ under air. A calcination temperature of $700^{\circ} \mathrm{C}$ was selected for the elimination of carbon since the lowest temperature for the total combustion of carbon is around $700^{\circ} \mathrm{C}$ (Schwickardi et al 2002). All the samples displayed a pure-phase perovskite structure after further calcination under air. It suggests that the formation of carbon under oxygen deficient condition did not lead to the obvious decrease in the high homogeneity of the metal ion mixing in the sample.

The crystalline sizes of LSCF powder obtained by the direct calcination of the solid precursor under air are $22.1 \mathrm{~nm}$ at a calcination temperature of $900^{\circ} \mathrm{C}$ for $5 \mathrm{~h}$ and $16.7 \mathrm{~nm}$ at $700^{\circ} \mathrm{C}$ for $5 \mathrm{~h}$. While it is only $13.9 \mathrm{~nm}$, when the solid precursor was first calcined under oxygen deficient condition at $900^{\circ} \mathrm{C}$ for $160 \mathrm{~min}$ and then further calcined at $700^{\circ} \mathrm{C}$ for $5 \mathrm{~h}$ under air. The same phenomenon was also found for the preparation of LSM. For the direct calcination under air, a crystalline size of $16 \cdot 1 \mathrm{~nm}$ was obtained at a calcination temperature of $900^{\circ} \mathrm{C}$, while a crystalline size of $13.2 \mathrm{~nm}$ was observed when the organic in the precursor was first converted to carbon. It

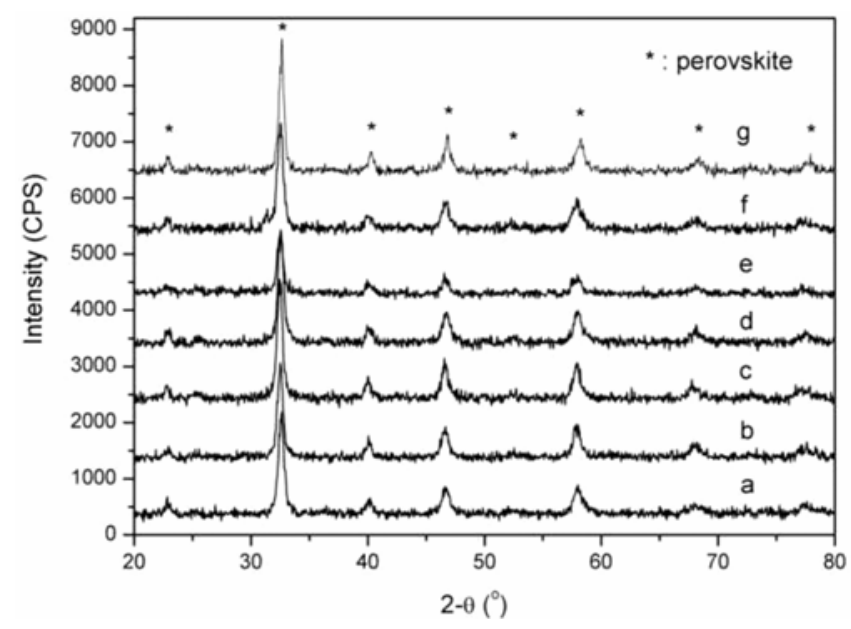

Figure 7. X-ray diffraction patterns of a-f: powders after further calcination under air at $700^{\circ} \mathrm{C}$ for $5 \mathrm{~h}$, for the samples obtained by calcining the solid precursor of LSCF under oxygen deficient condition at $900^{\circ} \mathrm{C}$ for a. $5 \mathrm{~min}$, b. $10 \mathrm{~min}$, c $20 \mathrm{~min}$, d. $40 \mathrm{~min}$, e. $80 \mathrm{~min}, \mathrm{f} .160 \mathrm{~min}$ and g. powders calcined by the solid precursor directly under air at $700^{\circ} \mathrm{C}$ for $5 \mathrm{~h}$ suggests that the pre-conversion of organic in solid precursor to carbon is beneficial in suppressing the grain growth of LSCF.

As compared to the activated carbon route (Ozawa and Kimura 1990; Schwickardi et al 2002; Liang et al 2004), the current process has intrinsic advantage. For the activated carbon route, the metal ions were dispersed over carbon surface and nanopores only by the physical adsorption. The strength of this kind of adsorption is weak and the segregation of metal ions easily occurred. Therefore, it is normally applicable for the synthesis of simple oxides such as binary and ternary oxides. For the synthesis of more complicated composite oxides such as LSCF, it was not so successful, at least by us. For the current in situ carbon templating process, however, the metal ions and carbon are mixed homogeneously in molecule level via chemical chelating during the preparation. The highly homogeneous mixing of the metal ions makes it possible to synthesize complicated mixed oxides such as LSCF and LSM at low temperatures.

For the preparation of porous electrode, some organic additive was usually added to electrode material as a pore former. After the calcination at high temperature, the organic was burnt out and left the vacancies in electrode body to form the pores. Carbon is also frequently used as the pore former (Wang et al 2004; Herzog et al 2004). The highly dispersed carbon in current carbon-perovskite mixture makes the current in situ carbon templating process also promising for the preparation of porous electrodes. By tuning the oxygen concentration and dwelling time during calcination of the solid precursor under oxygen deficient condition, the amount of carbon in the composite can be controlled. The porosity of the electrode is then determined by the amount of carbon in the carbonperovskite composite. The possibility of in situ carbon templated samples for the preparation of porous sintering

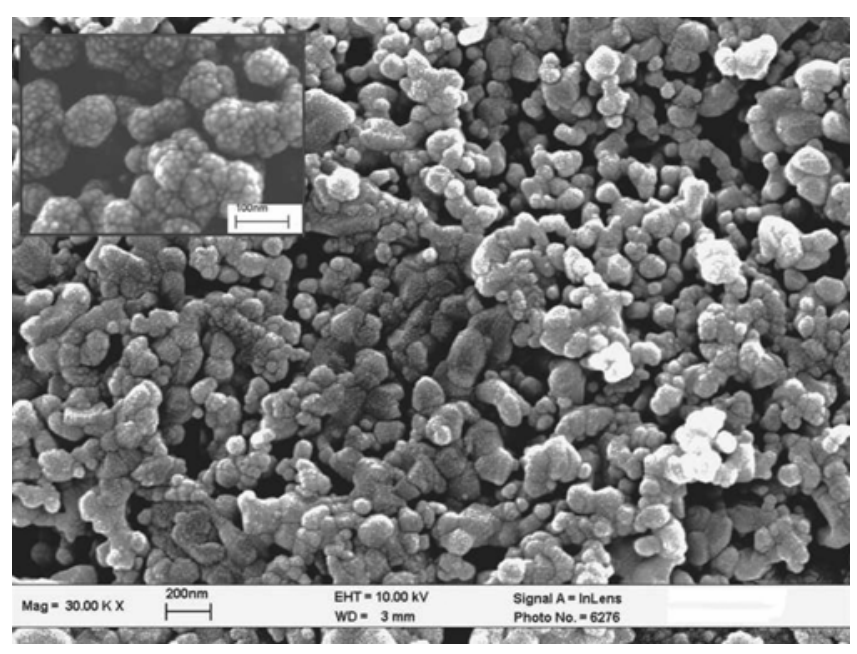

Figure 8. SEM surface morphologies of the as prepared porous LSCF pellet by the in situ carbon templating process calcined at $1000^{\circ} \mathrm{C}$ under air for $5 \mathrm{~h}$. 
body was investigated. The LSCF solid precursor was first calcined under an oxygen deficient atmosphere at $900^{\circ} \mathrm{C}$ for $160 \mathrm{~min}$, the obtained powder was then pressed into pellets, which were then calcined under air at $1000^{\circ} \mathrm{C}$ for $5 \mathrm{~h}$. Figure 8 shows the SEM surface morphologies of the obtained sintering pellets. The pellet is highly porous, with irregular pore configuration with size varying from several micro-meter to sub-nanometer to nanometer. A porosity as high as $75 \%$ was measured by the Archimedes method, which is much larger than that prepared by the normal process $(30-40 \%)$. As shown in figure 8 , the porous sintering body was constructed from nano particle with a particle size of $10-20 \mathrm{~nm}$, which ensured a high surface area for oxygen surface activation. Furthermore, it shows that the particles attached to each other firmly due to the high calcination temperature $\left(1000^{\circ} \mathrm{C}\right)$ was beneficial in reducing the interfacial polarization resistance for oxygen transportation. The high porosity and high surface area make the current in situ carbon templating process very promising for the preparation of porous electrode for functional application.

\section{Conclusions}

In the preparation of perovskite-type mixed oxides, EDTAcitrate combined complexing process allows the metal ions mixed in the molecule level homogeneously. With the optimized calcination parameters, the calcination of the solid precursor under oxygen deficient condition at high temperature led to the formation of perovskite phase and the creation of carbon simultaneously. Nano-sized LSCF-carbon and LSM-carbon composites were then obtained with a grain size of $20-30 \mathrm{~nm}$. Further calcination of the obtained composites under air results in the nano-sized pure-phase perovskites with the crystalline size of $14 \mathrm{~nm}$, which is smaller than that prepared by the calcination of the solid precursor under air directly (18$22 \mathrm{~nm}$ ). Such a decrease in crystalline size of perovskite via the indirect calcination process was ascribed to the suppressing effect of carbon in the grain growth of perovskite. Furthermore, when the in situ created carbon was applied as a template for pore forming, a highly porous perovskite sintering body packing from the nanosized perovskite oxide was obtained, which is promising for application as an electrode in solid oxide fuel cell.

\section{Acknowledgements}

This work was supported by the National Natural Science Foundation of China under contract Nos. 20646002, and
20676061, by the National 863 program under contract No. 2007AA05Z133, and by the National Basic Research Program of China under contract No. 2007 CB209704.

\section{References}

Boutz M M R, Winnubst L, Burggraaf A J and Carry M N C 1995 J. Am. Ceram. Soc. 78121

Fierro J L G 1990 Catal. Today 8153

Gunasekaran N, Saddawi S and Carberry J J 1996 J. Catal. 159 107

Hayashi M, Uemura H, Shimanoe K, Miura N and Yamazoe N 1998 Electrochem. Solid-State Lett. 1268

Herzog A, Klingner R, Vogt U and Graule T $2004 \mathrm{~J}$. Am. Ceram. Soc. 87784

Imaizumi S, Shimanoe K, Teraoka Y, Miura N and Yamazoe N 2004 J. Electrochem. Soc. 151 A1559

Liu Y, Zheng H T, Liu J R and Zhang T 2002 Chem. Eng. J. 89 213

Liang C H, Qiu J S, Li Z L and Li C 2004 Nanotechnology 15 843

Maguire E, Gharbage B, Marques F M B and Labrincha J A 2000 Solid State Ionics 127329

McEvoy A J 2001 J. Mater. Sci. 361087

Ozawa M and Kimura M 1990 J. Mater. Sci. Lett. 9446

Petunchi J O and Lombardo E A 1990 Catal. Today 8201

Rousseau B, Bassat J M, Blin A, Oliveira M S, Odier P, Marin C and Simon P 2004 Solid State Sci. 6131

Schwickardi M, Johann T, Schmidt W and Schuth F 2002 Chem. Mater. 143113

Shao Z P and Haile S M 2004 Nature 431170

Shao Z P, Yang W S, Cong Y, Dong H, Tong J H and Xiong G X 2000 J. Membr. Sci. 172177

Tai L-W, Nasrallah MM, Anderson H U, Sparlin D M and Schlin S R 1995 Solid State Ionics 76273

Teraoka Y, Zhang H M, Furukawa S and Yamazoe N 1985 Chem. Lett. 1743

Wang H, Sung I Y, Li X D and Kim D P 2004 J. Porous Mater. 11265

Weidenkaff A, Ebbinghaus S G and Lippert T 2002 Chem. Mater. 141797

Yamazoe N and Teraoka Y 1990 Catal. Today 8175

Yuasa M, Sakai G, Shimanoe K, Teraoka Y and Yamazoe N 2004 J. Electrochem. Soc. 151 A1477

Zhang Y L, Zha S W and Liu ML 2005 Adv. Mater. 17 487

Zhou W, Shao Z P and Jin W Q 2006 J. Alloy Compd. 426 368

Zhou W, Shao Z P, Ran R, Gu H X, Jin W Q and Xu N P 2008a J. Am. Ceram. Soc. 911155

Zhou W, Shao Z P, Ran R, Jin W Q and Xu N P 2008b Mater. Res. Bull. 432248 